\title{
Carreira Tradicional versus Carreira Autodirigida ou Proteana: um estudo comparativo sobre a satisfação com a carreira, a profissão e o trabalho
}

\author{
Guilherme Assunção de Andrade ${ }^{1}$ \\ Zélia Miranda Kilimnik² \\ Daniel Jardim Pardini ${ }^{3}$
}

\section{Resumo}

Este estudo objetivou verificar se as atitudes e os valores dos profissionais que atualmente se inserem ou se encontram no mercado de trabalho são mais aderentes à ideia da carreira tradicional ou à da carreira autodirigida/proteana. Buscou identificar, ainda, as âncoras de carreira dos entrevistados, o grau de satisfação com a carreira, com a profissão e com o trabalho, assim como a relação entre estas variáveis. O instrumento de coleta de dados utilizado foi o questionário, e a amostra foi composta por 113 estudantes de Graduação e de Pós-Graduação Lato e Stricto Sensu em Administração. Como resultado, encontrou-se a âncora de carreira "Estilo de Vida" com a média mais elevada, indicando a tendência de se buscar uma carreira que permita integrar as necessidades pessoais, familiares e de trabalho. Detectou-se aqui uma maior inclinação dos pesquisados para trilhar a carreira autodirigida ou proteana, e não foram encontradas correlações entre âncoras de carreira e satisfação com a carreira, indicando que não há determinada âncora que possa proporcionar maior satisfação profissional do que outra. O estudo contribui com a proposição de questões acerca do perfil de carreira que vem sendo adotado e com a identificação do nível de satisfação do profissional, além de recomendar uma revisão da escala de Âncoras de Carreira, de maneira a aumentar sua confiabilidade.

1 Mestre em Administração pela Universidade FUMEC. End.: Rua Bolívia, 178/apto 801, São Pedro, Belo Horizonte - MG. CEP: 30330-360 - Brasil. E-mail: guiandrade1970@gmail.com.

2 Mestre e Doutora em Administração pela Faculdade de Ciências Econômicas - FACE da Universidade Federal de Minas Gerais UFMG. Professora dos Cursos de Doutorado e Mestrado em Administração da Universidade FUMEC/MG. End.: Rua do Ouro 1920, apto 501A, Serra, Belo Horizonte - MG. CEP: 30210-590 - Brasil. E-mail: zeliamk@gmail.com.

3 Mestre e Doutor em Administração pela Faculdade de Ciências Econômicas - FACE da UFMG. Professor dos Cursos de Doutorado e Mestrado em Administração da Universidade FUMEC/MG. End.: Rua Caratinga, 60 apto 302, Bairro Anchieta. CEP: 30310-510 - Brasil. E-mail: pardini@face.fumec.br.

Artigo recebido em: 03/02/2010. Aceito em: 16/08/2010. Membro do Corpo Editorial Científico responsável pelo processo editorial: Emerson Antonio Maccari.

(c) (i) $($ ) $€$ Esta obra está sob uma Licença Creative Commons Atribuição-Uso. 
Palavras-chave: Carreira Tradicional. Carreira Autodirigida. Carreira Proteana. Satisfação com a Carreira. Satisfação com o Trabalho. Satisfação com a Profissão.

\section{Introdução}

Em um contexto no qual a tecnologia transforma o cenário do mercado de trabalho - reduzindo postos, extinguindo funções e exigindo novas competências - a carreira tradicional descaracteriza-se cada vez mais, dando espaço a novas formas de interação empregado-organização. Essa tendência não é recente. Suas origens remontam às últimas décadas do século passado. Como prenúncio dessa transformação, há as forças ambientais atuantes no final dos anos de 1980, tais como: a competição global aumentada, a recessão e a mudança na ênfase da administração para o gerenciamento da eficiência, que fizeram com que as organizações fossem compelidas à reestruturação, à redução de tamanho e à reinvenção de si próprias (REITMAN; SCHNEER, 2003).

Embora existam diferentes denominações para o novo tipo de carreira que emerge no mercado, parece haver um consenso sobre a sua configuração e características. Baruch (2004), por exemplo, destaca a transformação das "carreiras lineares", estáticas e rígidas em "carreiras multidirecionais" e dinâmicas, ressaltando que os modelos de carreira do futuro compreendem uma variedade de opções e de direções. Malvezzi (2000) vem denominar a carreira atual como "carreira sem fronteiras" - numa referência ao termo proposto por Arthur e Rousseau (1996) - "boundarylees career" - chamando os indivíduos nessa situação de "agentes econômico-reflexivos".

Hall (1986) denomina a nova carreira de "proteana". A denominação deriva do deus grego Proteu que, segundo a mitologia, possuía a habilidade de mudar de forma ao comando de sua vontade. Para o autor, o mito de Proteu revela elementos que podem ser metaforicamente observados no profissional contemporâneo que possui a habilidade de gerenciar sua própria carreira, de acordo com suas necessidades.

O aparecimento de carreiras proteanas nas organizações é sustentado por uma série de estudos. Por exemplo, pesquisas de Maguire (2002) na indústria de operação bancária constataram que aspectos relacionais do contrato psicológico entre empregados e organização tinham diminuído. Isso significa 
que componentes relacionais do contrato como comprometimento, lealdade à companhia e confiança na gerência, que tradicionalmente eram valorizados pelo sentido de "pertencimento", foram notadamente mudados.

Kilimnik, Castilho e Sant'anna (2006), em pesquisa realizada com mestrandos em Administração, detectaram que as pessoas sentem necessidade de desenvolver várias frentes de trabalho no atual contexto competitivo e globalizado dos negócios. Os profissionais estudados revelaram, inclusive, um perfil mais próximo do detentor da carreira proteana, com indicadores de uma maior autonomia e autodeterminação, evidenciados em suas trajetórias, assim como a busca pelo equilíbrio entre a vida pessoal e o trabalho. Os autores também identificaram neste estudo a tendência de carreiras "em ziguezague", em que se passa por diversas transições e se defronta com diversas alternativas, caracterizando o estilo proteano de carreira.

Em 1960, nos EUA, segundo Holoviak e Greenwood (2000), apenas dois em cada 100 indivíduos realizariam uma mudança radical nos rumos da sua carreira; em 1980 essa proporção já havia alcançado 35\% e, atualmente, continua em ascensão, sugerindo que a exceção de quatro décadas atrás pode vir a se tornar a regra.

Essas mudanças ocupacionais fazem parte do processo que Hall (1986) denominou "expansão da identidade": ampliação do repertório psíquico que resulta dos relacionamentos e experiências da trajetória profissional. Todo processo se caracteriza pelo contínuo aprendizado e pela busca de autenticidade e de sentido. Os profissionais contemporâneos pretenderiam realizar um trabalho que proporcionasse, além da subsistência, um sentido de autorrealização e autoexpressão. E a carreira proteana, conforme Martins (2001), seria capaz de integrar todas as dimensões e os papéis do indivíduo, na medida em que estabelece como objetivo final o sucesso psicológico, ou seja, o sucesso baseado em critérios pessoais.

Apesar de todos os autores citados confirmarem mudanças nas características da carreira tradicional, há estudos, como o de McDonald e o de Brown e Bradley (2004), que mostram a carreira tradicional, baseada no tempo de serviço, na mobilidade geográfica e em uma escalada constante acima da escada corporativa sendo ainda o modelo dominante em algumas organizações, como o setor público, mesmo que haja uma tendência para a carreira proteana.

Diante do contexto exposto, o qual indica que o período atual se caracteriza pela transição entre a carreira conhecida como tradicional e a chamada 
carreira proteana, esta pesquisa buscou responder três questões. Em primeiro lugar, buscou-se verificar se as atitudes dos profissionais que estão se inserindo ou já se inseriram no mercado de trabalho são mais aderentes à ideia da carreira tradicional ou mais sintonizadas com a ideia da carreira autodirigida ou proteana. Em segundo lugar, buscou-se identificar as âncoras de carreiras desses profissionais e o grau de satisfação com a carreira, com a profissão $e$ com o trabalho. Por fim, buscou-se identificar possíveis correlações entre essas variáveis.

\section{Carreiras}

O conceito de carreira pode ser dividido em duas fases distintas, conforme Chanlat (1995). O modelo tradicional, que vigorou até os anos de 1970, foi marcado pela estabilidade, enriquecimento, progresso e divisão sexual e social do trabalho, em que apenas os homens trabalhavam, ou seja, a possibilidade de ascensão pertencia apenas aos grupos socialmente dominantes. A progressão da carreira era linear e vertical e os trabalhadores possuíam maior estabilidade no emprego. Nessa abordagem, destacam-se, conforme Martins (2001), três aspectos que limitam o conceito de carreira. O primeiro é a noção de avanço, com a expectativa de progressão vertical na hierarquia de uma organização, acompanhada de sinais de crescente status e de ganhos financeiros. O segundo é a associação da carreira à profissão. Um médico, um militar ou um sacerdote teriam uma carreira, já um funcionário de escritório ou um operário de indústria não a teria. O terceiro é a pressuposição de uma estabilidade ocupacional em que o indivíduo sempre exerceria atividades relacionadas à sua profissão até a aposentadoria. A carreira, dentro dessa perspectiva, encontra-se mais relacionada ao trabalho assalariado e aos ocupantes de cargos existentes nas organizações.

Para McDonald, Brown e Bradley (2004), é típico do modelo tradicional requerer um padrão tipicamente masculino de trabalho, de tempo integral, para o mesmo empregador, por uma carreira inteira, com busca constante pelo avanço vertical e por recompensas externas.

A partir dos anos de 1970 o modelo moderno emerge resultante de mudanças sociais, tais como a maior participação da mulher no mercado de trabalho, a elevação dos graus de instrução, a afirmação do direito dos indivíduos, 
a globalização da economia e a flexibilização do trabalho (CHANLAT, 1995). Para o autor, a chegada maciça das mulheres, as mudanças tecnológicas e a reestruturação da economia introduziram novos comportamentos relacionados à carreira, como parar de trabalhar para estudar; estudar trabalhando; educar as crianças e voltar ao mercado de trabalho e aos estudos e reorientar a carreira mais frequentemente. Todos esses comportamentos introduziram rupturas no modelo de carreira tradicional, aproximando-a do modelo proteano. Esse novo modelo caracteriza-se por oportunidades para o profissional pertencente a grupos sociais variados, independentemente do sexo; pela progressão descontínua na carreira, por uma carreira mais horizontal do que vertical e por uma maior instabilidade.

Para Hall (1996), a carreira no Século XXI será predominantemente proteana, dirigida pelas pessoas, não pelas organizações, e reinventada de tempos em tempos. Esse conceito de "carreira proteana" foi criado em 1976 pelo autor e refere-se a um processo em que a própria pessoa, e não a organização, o gerencia. Nessa definição, a carreira proteana

[...] consiste de todas as variadas experiências da pessoa em educação, treinamento, trabalho em várias organizações, mudanças no campo ocupacional, etc.... As próprias escolhas pessoais de carreira e a busca por auto-realização da pessoa proteana são os elementos integrativos e unificadores em sua vida. O critério de sucesso é interno (sucesso psicológico), não externo. (HALL, 1996, p. 20)

Em contraste com a carreira tradicional, a carreira proteana é caracterizada pelos relacionamentos dirigidos pelo indivíduo e não pela organização, essa carreira está sujeita à reinvenção pela própria pessoa de tempos em tempos, a partir das mudanças no ambiente e na própria pessoa (HALL; MOSS, 1998). O novo modelo reivindica que as pessoas abandonem a nostalgia dos "velhos bons tempos", em que havia estabilidade nas organizações, para navegarem em suas próprias carreiras, guiadas por seus próprios objetivos.

McDonald, Brown e Bradley (2004) relacionam as diferenças entre carreira tradicional e proteana, conforme Quadro 1: 


\begin{tabular}{|l|l|l|}
\hline \multicolumn{1}{|c|}{ Área } & \multicolumn{1}{|c|}{ Tradicional } & \multicolumn{1}{c|}{ Proteana } \\
\hline Desenvolvimento & $\begin{array}{l}\text { Mobilidade geográfica, treina- } \\
\text { mento formal e objetivos de } \\
\text { Orientação para o empregado } \\
\text { Definição do sucesso no am- } \\
\text { longo prazo }\end{array}$ & $\begin{array}{l}\text { Aprento contínuo, envol- } \\
\text { vimento em projetos-chave } \\
\text { Autonomia, responsabilidade } \\
\text { Veloriza e serve a organização } \\
\text { pessoal e autodirecionamento } \\
\text { Relacionamento com a orga- } \\
\text { O fundamental é a tarefa e não } \\
\text { nização é importante, fornece } \\
\text { possibilidade de crescimento, } \\
\text { lealdade e comprometimento } \\
\text { nização; isso promove a inten- } \\
\text { sificação de oportunidades, } \\
\text { habilidades/conhecimentos }\end{array}$ \\
\hline
\end{tabular}

Quadro 1: Distinção entre carreira tradicional e proteana

Fonte: Mcdonald, Brown e Bradley (2004, p.115)

Apesar de mais democrático, o moderno modelo proteano de carreira se caracteriza pela instabilidade, descontinuidade e pela horizontalidade, em contraposição ao modelo tradicional. Essa mudança não significou, necessariamente, progresso e bem-estar para as pessoas, que se tornam as responsáveis por suas próprias carreiras. Além disso, ela envolve uma mudança no contrato psicológico entre os participantes, principalmente no quesito lealdade empregado-empresa (BALASSIANO; VENTURA; FONTES FILHO, 2004).

Para Balassiano, Ventura e Fontes Filho (2004), as premissas da carreira tradicional são voltadas eminentemente para as garantias de benefícios e de segurança. Já na carreira moderna, o sucesso está associado à trajetória pessoal (CHANLAT, 1995, MARTINS, 2001, HALL, 1986). Stroh, Brett e Reilly (1996) compararam dados coletados em 1978 e em 1989 e constataram, conforme diversos elementos de carreiras proteanas já descritos, que a satisfação com a empresa tinha diminuído, mas o envolvimento e a satisfação com o trabalho tinham aumentado.

Outra característica da carreira proteana é a delimitação do sucesso pela realização psicológica exclusiva do indivíduo, o que pode significar sentimentos de orgulho, realização pessoal ou felicidade familiar (HALL, 1996). Trata-se de um critério interno - sucesso psicológico, que depende do processo de autoconhecimento e ocorre paralelamente à expansão da identidade. Assim, o sucesso psicológico é representado pelo alcance de um conjunto de expectativas mútuas implícitas entre empregadores e empregados, focado nas contribuições de ambas as partes. Ao contrário do modelo relacional, baseado em relacionamento 
de comprometimento e confiança duradouro, o novo contrato é transacional, apoiado em trocas de curto prazo por benefícios e serviços (HALL, 1996).

Pelo conceito da aprendizagem contínua, o novo modelo de carreira não é mensurado pela idade cronológica e pelas etapas da vida, mas pelo contínuo aprendizado e mudança de identidade. As fontes de desenvolvimento passam a ser desafios no trabalho e nos relacionamentos. Treinamentos formais tornam-se menos relevantes do que o aprendizado alcançado na realização de trabalhos estimulantes e desafiadores (BALASSIANO; VENTURA; FONTES FILHO, 2004).

E, nesse cenário, o profissional passa a ser proprietário e administrador de sua carreira e a se perceber como unidade econômica autônoma, disputando espaço em um mercado de competências. Sua principal garantia seria a empregabilidade, que lhe determinaria a atratividade nesse mercado competitivo e instável. Assim, as carreiras tendem a se tornar curtos estágios de prospecção, experimentação, maestria e demissão, vividos em diversas empresas, estando o indivíduo sempre preparado e disposto a reiniciar o ciclo. (MARTINS, 2001).

\section{1 Âncoras de Carreira}

O conhecimento das pessoas sobre suas preferências profissionais as habilita para que façam opções mais conscientes (SCHEIN, 1990). Segundo esse autor, a perspectiva do desenvolvimento da carreira projeta o contínuo processo de ajustamento e compatibilidade entre o indivíduo e a organização. O elemento crucial neste ajustamento é definido como âncora de carreira, ou conjunto de autopercepções de talentos, motivações e atitudes, baseado em experiências efetivas que cada indivíduo desenvolve, em particular nos primeiros anos de carreira. Ela fornece uma crescente área de estabilidade nas atitudes individuais que ancoram a interpretação da carreira e as opções de vida.

Schein (1993) define "âncoras de carreira" como os elementos de nossa realidade que determinarão nossas preferências por certa ocupação, carreira, empresa ou oportunidade. Refletem a autopercepção de habilidades, as necessidades e os valores do indivíduo e são agrupadas em oito categorias: competência gerencial, competência técnica ou funcional, segurança e estabilidade, autonomia e independência, senso de serviço e dedicação à causa, desafio constante e estilo de vida. 


\begin{tabular}{|l|l|}
\hline \multicolumn{1}{|c|}{ Âncora } & \multicolumn{1}{c|}{ Definição } \\
\hline $\begin{array}{l}\text { Senso de Serviço e Dedicação } \\
\text { à Causa }\end{array}$ & $\begin{array}{l}\text { Utilização das capacidades interpessoais e de ajuda em serviço } \\
\text { dos outros, comprometimento com uma causa importante na } \\
\text { vida e a consequente devoção a ela. }\end{array}$ \\
\hline Competência Gerencial & $\begin{array}{l}\text { Compreende uma competência de gestão, reflete uma preocu- } \\
\text { pação central com a integração dos esforços dos outros, para } \\
\text { a responsabilidade pelos resultados totais e para a articulação } \\
\text { das diferentes funções de uma organização. }\end{array}$ \\
\hline Estilo de vida & $\begin{array}{l}\text { Busca desenvolver um estilo de vida capaz de equilibrar as } \\
\text { necessidades da carreira e da família, de modo que a pessoa } \\
\text { seja capaz de levar a vida à sua própria maneira. }\end{array}$ \\
\hline Desafio Constante & $\begin{array}{l}\text { Reflete uma preocupação primária com a resolução de proble- } \\
\text { mas aparentemente irresolúveis, de vencer oponentes duros, } \\
\text { de ultrapassar obstáculos difíceis. }\end{array}$ \\
\hline Autonomia e Independência & $\begin{array}{l}\text { Preocupação com a liberdade e a independência, com o não } \\
\text { ser constrangido pelas regras da organização, com o fazer as } \\
\text { coisas à sua maneira. }\end{array}$ \\
\hline Empreendedorismo & $\begin{array}{l}\text { Foco na criação de algo novo, envolvendo a motivação para } \\
\text { ultrapassar obstáculos, a vontade de correr riscos e o desejo de } \\
\text { proeminência pessoal naquilo que é alcançado. }\end{array}$ \\
\hline Segurança e Estabilidade & $\begin{array}{l}\text { Busca da estabilidade e garantia de emprego, segurança, be- } \\
\text { nefícios e boas condições de aposentadoria. }\end{array}$ \\
\hline $\begin{array}{l}\text { Competência Técnica ou } \\
\text { Funcional }\end{array}$ & $\begin{array}{l}\text { Foco no desenvolvimento da perícia pessoal e especialização, } \\
\text { construção da carreira em uma área técnica específica ou em } \\
\text { uma determinada profissão. }\end{array}$ \\
\hline
\end{tabular}

Quadro 2: Definição das Âncoras de Carreira

Fonte: Adaptado de Schein (1990)

As âncoras de carreira na vida profissional de uma pessoa podem ser utilizadas como formas de organizar experiências, identificar áreas de contribuição ao longo de sua trajetória, gerar critérios para tipos de trabalho e identificar padrões de ambição e sucesso que a pessoa pode determinar para si mesma. Elas servem, portanto, para guiar, balizar, estabilizar e integrar a carreira de uma pessoa (KILIMNIK; CASTILHO; SANT'ANNA, 2006). Os trabalhos de Schein (1990) permitem agregar a preferência profissional efetiva à busca da carreira, contrapondo-a aos estereótipos de sucesso que apontam para o sucesso financeiro e social. 
Kilimnik et al. (2008) buscaram investigar, em um estudo comparativo e longitudinal de casos, as autopercepções e as aspirações (âncoras) de carreira de profissionais de Administração, bem como a evolução do conceito de carreira e seus diversos significados. Foram realizadas entrevistas, conjugadas com a aplicação do Inventário de Âncoras de Carreira de Edgar Schein (1993), instrumento esse que foi reaplicado em 12 profissionais do grupo original, após um período de dois anos, juntamente com uma nova entrevista. A âncora Estilo de Vida foi a mais encontrada, nas duas aplicações, refletindo a necessidade de equilibrar a vida familiar e o trabalho. Observou-se, também, que as principais âncoras diagnosticadas geralmente permaneceram como tais, mas, em alguns casos, as posições se inverteram, com âncoras secundárias passando para o primeiro plano. Em outros casos, inclusive, constatou-se uma reconfiguração das âncoras, concomitantemente com as trajetórias de carreira dos pesquisados que mudaram de um perfil tradicional para um mais sintonizado com tendências atuais. Determinadas alterações nas âncoras, muito provavelmente, estão relacionadas a novas demandas da carreira que, paradoxalmente, podem estar levando alguns profissionais a deixarem de lado, ainda que temporariamente, seus valores e aspirações.

Em outro estudo, Rodrigues, Bouzada e Kilimnik (2007) investigaram as âncoras de carreira de 87 alunos do curso de Administração de Empresas, cursando o $6^{\circ}, 7^{\circ}$ e $8^{\circ}$ períodos e 38 mestrandos em Administração, de uma universidade particular. No grupo dos graduandos, as principais âncoras foram Estilo de Vida e Segurança no Trabalho, com predominância da primeira, demonstrando, assim, uma aspiração por melhor qualidade de vida, associada a uma necessidade de estabilidade profissional. Já, entre os alunos de mestrado, as principais âncoras encontradas foram: Estilo de vida, Autonomia e Desafio Puro, nessa ordem de importância, demonstrando que, embora esses profissionais também estejam em busca de um equilíbrio entre a vida profissional e a familiar, eles demonstram uma forte tendência para a carreira proteana $e$ uma menor influência de valores associados à carreira tradicional.

Ambos os estudos indicam uma tendência no sentido de predominância da âncora estilo de vida, pelo menos, no que se refere a alunos e profissionais da área de Administração. 


\section{A Busca de Satisfação no Trabalho}

A satisfação no ambiente de trabalho é a de um fator crítico e dinâmico, que pode variar de pessoa para pessoa e na mesma pessoa, de tempo em tempo.

Para Lawler e Porter (1978), as atividades que as pessoas executam são as fontes mais importantes de satisfação nas organizações. As pesquisas realizadas por esses autores mostram que é o próprio desempenho que mais satisfaz as pessoas por meio de recompensas intrínsecas como a gratificação de se fazer um trabalho bem feito.

Os pesquisadores Hackman e Oldham (1975) chegaram à conclusão de que os resultados pessoais e organizacionais - alta motivação interna, alta satisfação no trabalho, alta qualidade no desempenho e baixo absenteísmo $e$ turnover - são obtidos quando estão presentes os seguintes estados psicológicos criados por um trabalho rico em conteúdo: a) a percepção de significância que se refere ao grau em que o indivíduo percebe o trabalho como importante, valioso e significativo; b) a percepção de responsabilidade, que se relaciona com sentir-se pessoalmente responsável pelos resultados do seu trabalho; e c) o conhecimento dos resultados do trabalho, ou seja, o grau em que o indivíduo recebe informações, em uma base regular, sobre quão bem está efetivamente executando a tarefa. Dessa forma, quanto maior a intensidade da presença desses estados nos indivíduos, maiores serão a predisposição e a motivação para o trabalho.

Para Drucker (1999), a satisfação no trabalho não se refere apenas aos conhecimentos formais, mas à capacidade de saber quem somos, qual o nosso lugar, nossas aptidões, nosso temperamento, nossas reais capacidades de realização do que queremos. Portanto, aprender a assumir essa responsabilidade de administrar a nós próprios não é um desafio simples e, segundo o autor, ninguém nos ensina isso - nenhuma escola, nenhuma universidade (DRUCKER, 1999).

\section{Procedimentos Metodológicos}

O presente estudo adota a abordagem quantitativa, definida por Oliveira (1997, p. 115) como: 
[...] o tipo de pesquisa que, como o próprio termo indica, quantifica opiniões, dados, na forma de coleta de informações, assim como também o emprego de recursos e técnicas estatísticas desde as mais simples, como percentagem, média, moda, mediana e desvio padrão, até as de uso mais complexo como coeficiente de correlação, análise de correlação, normalmente utilizadas nas defesas de tese.

Trata-se de uma pesquisa descritiva, pois descreve o nível de satisfação dos indivíduos com seu trabalho, profissão e carreira, assim como suas âncoras, além de descrever o perfil da sua carreira, se é tradicional ou proteana.

No entendimento de Vergara (2005), a amostra da pesquisa é considerada o conjunto de elementos selecionados de acordo com algum critério de representatividade. A amostra da pesquisa é composta por 113 respondentes, alunos que atuam em áreas profissionais diversificadas, e que atualmente cursam graduação e pós-graduação lato e stricto sensu em Administração nas escolas particulares da Grande Belo Horizonte. O critério utilizado foi o não probabilístico, por acessibilidade.

A coleta de dados foi realizada essencialmente por meio de questionário composto pela escala de Âncoras de Carreira de Edgar Schein e de duas outras escalas, com questões sobre a carreira tradicional e proteana, assim como sobre a satisfação com a carreira, o trabalho e a profissão.

As dimensões pesquisadas - a) tipo de carreira tradicional x proteana; b) Âncoras de Carreira; c) satisfação com trabalho, carreira e profissão - foram medidas por meio de uma escala itemizada, com número par de categorias e balanceada, ou seja, com o mesmo número de categorias favoráveis e desfavoráveis. Segundo Malhotra (2006), uma escala itemizada apresenta números ou uma breve descrição associada a uma dada categoria. Os dados foram analisados por meio de estatística descritiva. Adotou-se a média como medida de tendência central e o coeficiente de variação como medida de dispersão.

De acordo com Levine, Bereson e Stephan (2000), somente é possível comparar a variabilidade de dados que têm média igual. Como solução para esse problema, pode ser usado o coeficiente de variação, pois é uma medida que permite a comparação de dois ou mais conjuntos de dados. Isso porque ele expressa a variabilidade como uma proporção da média e é calculado dividindo o desvio padrão da variável pela média. Varia de 0 a 1 sendo que quanto mais próximo de 1, maior a variabilidade dos dados. Quanto maior a 
variabilidade dos dados, menor é o consenso sobre a opinião dos respondentes, ou seja, a média pode ser mais próxima dos extremos positivo ou negativo e não significar que a maioria, em média, concorda com essa posição. Outra interpretação para coeficientes de variação elevados é que a média é baixa.

Como a média apresenta uma limitação por ser sensivel a valores extremos optou-se por utilizar também um gráfico com as frequências relativas a cada variável para que os dados pudessem ser observados sob outra perspectiva. A frequência relativa permite demonstrar quantas vezes cada valor dentro da escala foi marcado de forma a compará-los.

Adotou-se também a análise de correlação utilizando o coeficiente de Spearman, uma vez que esse coeficiente não requer a suposição de que a relação entre as variáveis é linear (MALHOTRA, 2006). Tal coeficiente varia de -1 a +1 , sendo que o valor zero representa uma correlação nula. Dessa forma, a análise de correlação permite identificar se as variáveis evoluem no mesmo sentido (quando há correlação positiva); se evoluem em sentido contrário (correlação negativa); ou se não existe um padrão na variação, que seria a correlação igual a zero (LEVINE; BERESON; STEPHAN, 2000).

Foram verificadas correlações entre as dimensões das âncoras de carreira, das satisfações e do tipo de carreira. Tais dimensões foram mensuradas por meio do valor médio das variáveis que mediam cada uma.

\section{Apresentação e Análise dos Resultados}

\subsection{Caracterização da Amostra}

A amostra foi composta por $55,9 \%$ de homens e $41,5 \%$ de mulheres. No que tange à faixa etária dos respondentes, grande parte da amostra tem entre 24 e 44 anos, perfazendo um total de $89,3 \%$ dos respondentes. No que se refere ao tempo de trabalho, a maior parte concentra-se na faixa de 1 a 5 anos $(39,9 \%)$, e apenas $3,7 \%$ dos respondentes já trabalham na faixa de 20 a 25 anos. Com relação à profissão, enquanto 37,2\% são administradores, 60,1 \% exercem outras profissões. No que tange ao nível do cargo dos respondentes, um percentual considerável é analista/técnico (46,8\%), seguido por profissionais liberais $(17,6 \%)$ e por supervisores/coordenadores $(17,0 \%)$. 


\section{2 Âncoras de Carreira}

De acordo com os resultados apurados na pesquisa (Tabela 1), em relação às âncoras de carreira, as que apresentaram maiores médias e menores coeficientes de variação, ou seja, maior homogeneidade, foram, em ordem decrescente: estilo de vida, competência técnico-profissional e desafio puro. A variável que apresentou a média mais elevada, dentro da âncora Estilo de Vida, diz respeito a se ter uma carreira que permita integrar as necessidades pessoais, familiares e de trabalho, o que confirma resultados de pesquisas de Kilimnik et al. (2008) e Rodrigues, Bouzada e Kilimnik (2007), citadas anteriormente.

As médias das outras dimensões ficaram entre 3,00 e 4,00, sendo que a autonomia encabeçou essa lista, seguida de serviço e dedicação e das demais como segurança, empreendedorismo e gerir pessoas. Essa última foi a que apresentou a menor média.

Tabela 1: Estatística descritiva das âncoras de carreira

\begin{tabular}{|l|c|c|c|}
\hline \multicolumn{1}{|c|}{ Dimensões } & Média & Desvio-Padrão & $\begin{array}{c}\text { Coeficiente de } \\
\text { variação }\end{array}$ \\
\hline D1.1. Competência técnico-profissional & 4,13 & 0,77 & 0,19 \\
\hline D1.2. Gerir pessoas & 3,63 & 0,93 & 0,25 \\
\hline D1.3. Autonomia & 3,99 & 0,97 & 0,24 \\
\hline D1.4. Segurança & 3,84 & 1,00 & 0,26 \\
\hline D1.5. Empreendedorismo & 3,70 & 1,12 & 0,30 \\
\hline D1.6. Serviço e dedicação & 3,95 & 0,94 & 0,24 \\
\hline D1.7. Desafio Puro & 4,11 & 0,83 & 0,20 \\
\hline D1.8. Estilo de vida & 4,63 & 0,80 & 0,17 \\
\hline
\end{tabular}

Fonte: Dados da pesquisa

Buscou-se verificar as correlações existentes entre as dimensões que compõem as âncoras de carreira, conforme se observa na Tabela 2: 
Tabela 2: Correlação entre as âncoras de carreira

\begin{tabular}{|c|c|c|c|c|c|c|c|}
\hline $\begin{array}{c}\text { Âncoras de } \\
\text { carreira }\end{array}$ & D1.1 & D1.2 & D1.3 & D1.4 & D1.5 & D1.6 & D1.7 \\
\hline $\begin{array}{l}\text { D1.1.Competência téc- } \\
\text { nico-profissional }\end{array}$ & - & - & - & - & - & - & - \\
\hline D1.2. Gerir pessoas & $0,097^{\mathrm{NS}}$ & - & - & - & - & - & - \\
\hline D1.3. Autonomia & $0,268 * *$ & $0,361 * *$ & - & - & - & - & - \\
\hline D1.4. Segurança & $0,270 * *$ & $0,102^{\mathrm{NS}}$ & $-0,017^{\mathrm{NS}}$ & - & - & - & - \\
\hline $\begin{array}{l}\text { D1.5. Empreendedo- } \\
\text { rismo }\end{array}$ & $0,390 * *$ & $0,304 * *$ & $0,484 * *$ & $0,192 * *$ & - & - & - \\
\hline $\begin{array}{l}\text { D1.6. Serviço e dedi- } \\
\text { cação }\end{array}$ & $0,402 * *$ & $-0,039^{\text {NS }}$ & $0,145^{*}$ & $0,082^{\mathrm{NS}}$ & $0,156^{*}$ & - & - \\
\hline D1.7. Desafio Puro & $0,382 * *$ & $0,378 * *$ & $0,138^{\mathrm{NS}}$ & $-0,016^{\mathrm{NS}}$ & $0,248 * *$ & $0,302 * *$ & - \\
\hline D1.8. Estilo de vida & $0,349 * *$ & $0,049^{\mathrm{NS}}$ & $0,209 * *$ & $0,199 * *$ & $0,119^{\mathrm{NS}}$ & $0,253 * *$ & $0,212 * *$ \\
\hline
\end{tabular}

Fonte: Dados da pesquisa

As correlações consideradas moderadas foram encontradas entre a dimensão Autonomia e Empreendedorismo e entre Competência técnico-profissional e Serviço e dedicação. Isso significa que existe um padrão de variação entre essas variáveis.

As correlações entre todas as outras âncoras podem ser consideradas fracas, inclusive a existente entre Desafio Puro e Empreendedorismo, resultado esse um tanto surpreendente, pois essas duas variáveis estão presentes e interligadas na definição da Carreira Proteana.

\subsection{Escalas de Satisfação}

Na presente pesquisa buscou-se mensurar a satisfação com o trabalho, a profissão e com a carreira (ver Tabela 3): 
Tabela 3: Estatística descritiva das dimensões da satisfação

\begin{tabular}{|l|c|c|c|}
\hline \multicolumn{1}{|c|}{ Variável/Dimensão } & Média & Desvio-Padrão & $\begin{array}{c}\text { Coeficiente } \\
\text { de variação }\end{array}$ \\
\hline D2.1. Satisfação com o trabalho & 4,42 & 0,89 & 0,20 \\
\hline D2.2. Satisfação com a profissão & 4,01 & 0,80 & 0,20 \\
\hline D2.3. Satisfação com a carreira & 4,09 & 1,00 & 0,24 \\
\hline
\end{tabular}

Fonte: Dados da pesquisa

Com relação à medida das dimensões da satisfação, a que obteve maior média foi a satisfação com o trabalho; e a que obteve a menor foi a satisfação com a profissão. Com relação ao coeficiente de variação não foram observados valores muito diferentes entre as variáveis. Esse fato talvez se relacione com o perfil da amostra, composta por indivíduos mais jovens, menos maduros e com menos tempo de carreira.

No que se refere à satisfação com o trabalho, profissão e carreira, destacaram-se as seguintes assertivas, com as maiores médias, a saber: "[...] sentir que faço bem o meu trabalho é uma das maiores recompensas que tenho [...]", $e$ "[...] considero que o sucesso na carreira pode ser avaliado com base em sentimentos de orgulho e realização pessoal"; dimensões que são consideradas como fundamentais no escopo da moderna orientação profissional, conforme argumenta Martins (2001).

Também foi verificada a correlação existente entre as dimensões da satisfação com as dimensões de âncoras de carreira e entre as próprias dimensões de satisfação, conforme mostra a Tabela 4:

Tabela 4: Correlação das âncoras de carreira com as escalas de satisfação e das escalas de satisfação entre si

\begin{tabular}{|l|c|c|c|}
\hline \multirow{2}{*}{ Âncoras de carreira } & \multicolumn{3}{|c|}{ Satisfação } \\
\cline { 2 - 4 } & D2.1 Trabalho & D2.2 Profissão & D2.3 Carreira \\
\hline $\begin{array}{l}\text { D1.1. Competência técnico-pro- } \\
\text { fissional }\end{array}$ & $\mathbf{0 , 2 2 4 ^ { * * }}$ & $\mathbf{0 , 3 0 0 ^ { * * }}$ & $\mathbf{0 , 2 1 4 ^ { * * }}$ \\
\hline D1.2. Gerir pessoas & $-0,003^{\mathrm{NS}}$ & $0,099^{\mathrm{NS}}$ & $\mathbf{0 , 1 6 0 ^ { * }}$ \\
\hline D1.3. Autonomia & $-0,083^{\mathrm{NS}}$ & $0,060^{\mathrm{NS}}$ & $-0,036^{\mathrm{NS}}$ \\
\hline D1.4. Segurança & $0,013^{\mathrm{NS}}$ & $0,084^{\mathrm{NS}}$ & $0,052^{\mathrm{NS}}$ \\
\hline D1.5. Empreendedorismo & $-0,070^{\mathrm{NS}}$ & $0,074^{\mathrm{NS}}$ & $0,013^{\mathrm{NS}}$ \\
\hline D1.6. Serviço e dedicação & $0,178^{*}$ & $0,135^{\mathrm{NS}}$ & $0,055^{\mathrm{NS}}$ \\
\hline
\end{tabular}




\begin{tabular}{|c|c|c|c|}
\hline \multirow{2}{*}{ Âncoras de carreira } & \multicolumn{3}{|c|}{ Satisfação } \\
\hline & D2.1 Trabalho & D2.2 Profissão & D2.3 Carreira \\
\hline D1.7. Desafio Puro & $0,275 * *$ & $0,263 * *$ & $0,316 * *$ \\
\hline D1.8. Estilo de vida & $0,164^{*}$ & $0,169 *$ & $0,090^{\mathrm{NS}}$ \\
\hline D2.1. Trabalho & - & - & - \\
\hline D2.2. Profissão & $0,454 * *$ & - & - \\
\hline D2.3. Carreira & $0,682 * *$ & $0,586 * *$ & - \\
\hline
\end{tabular}

Fonte: Dados da pesquisa

Com relação às correlações existentes entre as dimensões da satisfação e das âncoras de carreira, é possível observar na Tabela 4 que as âncoras Autonomia, Segurança e Empreendedorismo não apresentam correlações significativas com nenhuma das dimensões da satisfação. As âncoras Competência técnico-profissional e Desafio Puro apresentam correlação fraca comparada a todas as dimensões da satisfação. Já as correlações significativas consideradas muito fracas foram observadas entre Gerir pessoas e satisfação com a carreira, Serviço e dedicação e satisfação com o trabalho, e Estilo de vida com satisfação com o trabalho e com a profissão.

Conclui-se que, nas correlações entre as âncoras de carreiras e as dimensões de satisfação foram encontrados valores indicadores de correlação inexistente, muito fraca ou fraca, indicando que o fato de o indivíduo possuir uma âncora não é indicador de uma maior ou menor satisfação no trabalho, na profissão ou na carreira - o que confirma a ideia implícita, no modelo de Edgar Schein (1990), de que não existe uma âncora melhor do que outra, apenas as pessoas variam no que se refere aos seus valores e inclinações quanto à carreira.

No que tange à correlação entre as dimensões da satisfação pode-se observar que todas apresentam correlação significativa e moderada entre si.

\subsection{Tipos de Carreira}

A Tabela 5 mostra que a média da Carreira Proteana é maior do que a média da Carreira Tradicional, assim como seu coeficiente de variação é menor. Tais resultados evidenciam que os respondentes têm uma maior inclinação para a Carreira Proteana. 
Tabela 5: Estatística descritiva dos tipos de carreira

\begin{tabular}{|c|c|c|c|}
\hline Variável/Dimensão & Média & Desvio- Padrão & Coeficiente de variação \\
\hline Carreira proteana & 4,41 & 0,70 & 0,16 \\
\hline Carreira tradicional & 3,66 & 0,74 & 0,20 \\
\hline
\end{tabular}

Fonte: Dados da pesquisa

Verificou-se ainda a correlação das dimensões do tipo de carreira com as âncoras de carreira, com as dimensões da satisfação e dos tipos de carreira entre si. Os resultados mostram alguns padrões interessantes, que distinguem a Carreira Proteana da Carreira Tradicional, conforme Tabela 6:

Tabela 6: Correlação das escalas de carreira com as âncoras de carreira, com as escalas de satisfação e com elas mesmas

\begin{tabular}{|l|c|c|}
\hline \multirow{2}{*}{\multicolumn{2}{|c|}{ Âncoras de carreira }} & \multicolumn{2}{c|}{ Carreira } \\
\cline { 2 - 3 } & D3.1 Proteana & D3.2 Tradicional \\
\hline D1.1. Competência técnico-profissional & $0,251^{* *}$ & $0,252^{* *}$ \\
\hline D1.2. Gerir pessoas & $0,274^{* *}$ & $0,223^{* *}$ \\
\hline D1.3. Autonomia & $0,301^{* *}$ & $0,153^{*}$ \\
\hline D1.4. Segurança & $0,031^{\mathrm{NS}}$ & $0,447^{* *}$ \\
\hline D1.5. Empreendedorismo & $0,115^{\mathrm{NS}}$ & $0,309^{* *}$ \\
\hline D1.6. Serviço e dedicação & $0,246^{* *}$ & $0,101^{\mathrm{NS}}$ \\
\hline D1.7. Desafio Puro & $0,409^{* *}$ & $0,262^{* *}$ \\
\hline D1.8. Estilo de vida & $0,284^{* *}$ & $0,277^{* *}$ \\
\hline D2.1. Satisfação com o trabalho & $0,000^{\mathrm{NS}}$ & $0,074^{\mathrm{NS}}$ \\
\hline D2.2. Satisfação com a profissão & $0,109^{\mathrm{NS}}$ & $0,120^{\mathrm{NS}}$ \\
\hline D2.3.Satisfação com a carreira & $0,074^{\mathrm{NS}}$ & $0,096^{\mathrm{NS}}$ \\
\hline D3.1. Carreira proteana & & $0,123^{\mathrm{NS}}$ \\
\hline D3.2. Carreira tradicional & $0,123^{\mathrm{NS}}$ & - \\
\hline **Correlação significativa ao nível de 1\% & & \\
*Correlação significativa ao nível de 5\% & & \\
Ns Correlação não significativa ao nível de 5\% & & \\
\hline
\end{tabular}

Fonte: Dados da pesquisa

Competência técnico-profissional, Gerir pessoas e Estilo de Vida apresentam correlação significativa fraca, tanto com a Carreira Proteana quanto com a Carreira Tradicional. A Autonomia, apesar de apresentar correlação 
significativa com ambos os tipos de carreira, apresenta correlação fraca com Carreira Proteana e correlação muito fraca com Carreira Tradicional.

A primeira observação interessante a se fazer é entre as âncoras Segurança e Empreendedorismo e a Carreira Tradicional. A correlação entre a âncora Segurança e a Carreira Tradicional é significativa e apresenta um valor moderado. A correlação das variáveis Empreendedorismo e Carreira Tradicional também é significativa embora apresente um valor fraco. Já as correlações entre as âncoras Segurança e Empreendedorismo com Carreira Proteana não foram significativas. Outra observação interessante é a correlação existente entre a âncora Desafio Puro e a Carreira Proteana. Nesse caso, a correlação é significativa e moderada enquanto a correlação entre Desafio Puro e Carreira Tradicional é significativa, porém fraca. Serviço e dedicação e Carreira Proteana apresentam padrão semelhante. A diferença é que a correlação entre Serviço e dedicação e Carreira Proteana é fraca.

A maior correlação da Carreira Proteana é com o Desafio Puro e da Tradicional com a Segurança, resultados bastante condizentes, considerando o significado de cada uma dessas variáveis.

\section{Considerações Finais}

A âncora de carreira predominante entre os profissionais pesquisados foi "Estilo de Vida", o que demonstra a importância atribuída à busca pelo equilíbrio entre vida familiar e trabalho.

O estudo também indica maior inclinação dos pesquisados em direção aos valores da carreira proteana, o que reflete a valorização de um processo de carreira autogerenciado, com critérios de satisfação definidos pelos indivíduos e não pelas organizações. Mostra o desejo dos indivíduos por uma carreira mais flexível, que possa ser alterada conforme as mudanças de valores, habilidades ou desejos em suas trajetórias de vida. Esse aspecto é coerente com a maior incidência da âncora Estilo de Vida na pesquisa.

Esses dois aspectos geram insights para a área de Gestão de Pessoas das organizações, no sentido de se prepararem para oferecerem carreiras mais flexíveis, que valorizem não apenas aspectos externos, como status ou recompensas financeiras, mas também os sentimentos internos de realização dos indivíduos, como o desejo por mais aprendizado e por mudanças. E, também, por equilíbrio entre o trabalho e a vida pessoal e familiar. 
A âncora mais associada à carreira tradicional foi a Segurança, um resultado coerente, uma vez que a expectativa do empregado na carreira tradicional é a segurança de emprego por parte do empregador, que, por sua vez, espera a lealdade e o comprometimento do empregado em retribuição. Já a âncora mais associada à carreira proteana foi Desafio Puro. A princípio, esta não parece ser a conjugação mais coerente, uma vez que a carreira proteana abre espaço para a busca de satisfação por meio de outros critérios, como satisfação, equilíbrio, autonomia e liberdade. Esse equilíbrio, bem representando pela âncora Estilo de Vida, não se mostra presente na âncora Desafio Puro, que valoriza uma preocupação primordial como a resolução de problemas aparentemente irresolúveis, de vencer oponentes duros. Ao que tudo indica, as pessoas estão percebendo a carreira proteana como algo bastante desafiante e que envolve riscos.

A satisfação maior se deu com o trabalho, um resultado interessante $e$ também coerente com os valores da carreira proteana. Nela, o mais importante é a satisfação que o trabalho traz para o sentimento de realização do indivíduo. A satisfação com o trabalho se torna mais importante para o indivíduo proteano do que a sua profissão ou trajetória.

No que se refere às correlações entre as âncoras de carreiras, tipos de carreira e as dimensões de satisfação foram encontrados valores indicadores de correlação inexistente, muito fraca ou fraca. Indicando que o fato de o indivíduo possuir uma âncora ou de optar por a determinado tipo de carreira (proteana ou tradicional) não está associado a maior ou a menor satisfação no trabalho, na profissão ou na carreira.

Como era de se esperar também não foi encontrada correlação entre os dois tipos de carreira, o que consiste em um aspecto positivo já que, por definição, a carreira proteana possui características bastante diferentes, senão antagônicas, em relação à carreira tradicional.

Este estudo apresentou como limitação o fato de ter utilizado escalas compostas de questões que apresentaram médias discrepantes em relação às demais variáveis do seu grupo, acompanhadas de coeficientes de variação muito elevados, indicando grande diversidade de opinião com relação a essas questões. O fato de mais de $37 \%$ da amostra ser constituído por administradores pode ter influenciado os resultados, tornando-os mais relacionados a esse perfil profissional.

A escala de âncoras de carreira utilizada, que consistiu em uma tradução da escala original em inglês apresentou algumas limitações. No instrumento de 
Edgar Schein existem oito dimensões pré-estabelecidas, sendo que cada uma possui cinco indicadores. Entretanto, quando se realiza uma análise fatorial exploratória para verificar as dimensões, o resultado fica muito diferente do proposto por Schein. Indicadores que teoricamente pertencem a uma dimensão passam a fazer parte de outra. Uma evidência adicional é de que é extremamente improvável que ao realizar uma análise fatorial todas as dimensões fiquem com o número exato de indicadores, como é o caso da escala de Schein, que ficou com cinco. Outro problema relativo a essa escala reside nos significados atribuídos aos valores da escala. Cada número não tem um significado próprio e único, ou seja, foram oferecidas apenas quatro diferenciais semânticos para seis opções numéricas. Dessa forma, sugere-se procedimentos e pesquisas que contribuam para a revisão e validação desse instrumento, de modo a aumentar sua confiabilidade.

\section{Traditional Career versus Self-Directed or Protean Career: a comparative study of satisfaction with career, profession and work}

\section{Abstract}

This research has analyzed if the attitudes and values of news professionals are more adherent to the traditional idea of career or self-directed/protean careers. The objectives were to identify the anchors of respondents' careers, the degree of satisfaction towards their careers, professions and work and the relationship between these variables and their career profiles. The data collection instrument used was a questionnaire and a sample consisted of 113 graduate and undergraduate students in the area of Administration. As a result, we have found the "Lifestyle" career anchor with the highest average, indicating a tendency to pursue a career that allows integrating personal, family and work lives. We have detected a trend of the subjects to track the protean career. And no correlation was found between career anchors and career satisfaction, indicating that there is not a specific anchor that could provide greater work satisfaction than others. The study contributes to the proposition questions about the career profile that has been used, with the identification of the level of professional satisfaction. Besides it has indicated there should be a revision of the scale of Career Anchors, in order to increase its reliability. 
Key words: Traditional Career. Self-Directed Career. Protean Career. Satisfaction with Career. Job Satisfaction. Satisfaction with the Profession.

\section{Referências}

ARTHUR, M. B; ROUSSEAU, D. M. (Ed.). The boundary less career: a new employment principle for a new organizational era. Oxford: Oxford University Press, 1996.

BAGGIO, L.; LIMA, I.; KOVALESKI, J. A satisfação do trabalhador na área industrial: o caso da indústria madeireira "PP". In: ENCONTRO NACIONAL DE ENGENHARIA DA PRODUÇÃO, 26, 2006, Fortaleza... ABEPRO, 2006.

BALASSIANO, M.; FONTES FILHO, J.; VENTURA, E. Carreiras e Cidades: Existiria um Melhor Lugar para se Fazer Carreira? Revista de Administração Contemporânea, v. 8, n. 3, jul./set. 2004.

BARUCH, Y. Transforming careers: from linear to multidirecional career paths: Organizational and Individual Perspectives. Career Development International, v. 9, n. 1, p. 58-73, 2004.

CHANLAT, J. Quais carreiras e para qual sociedade?(I). In: Revista da Administração de Empresas, São Paulo, v. 35, n. 6, p. 67-75, nov./dez., 1995.

DRUCKER, P. Você está preparado? Revista Idéias e Pessoas Online. Trecho da conferência "Redefinindo Lideranças, organizações e comunidades", de 9/11/1999 - Fundação Peter Drucker). Disponível em: <www.mfn.com.br/ip/conteudo/esta_ preparado.htm>. Acesso em: 11/04/2007.

HACKMAN, J. R.; OLDHAM,G. R. Development of the job diagnostic survey. Journal of applied Psychology, v. 60, n. 2, p. 159-170, 1975.

HALL, D. Career Development Comes of Age. Training \& Development Journal, v. 40, Issue 11, p. 16-18, november 1986.

HALL, D. T. Protean careers of the 21st century. Academy of Management Executive, v. 10, n. 4, p. 8-16, 1996. 
HALL, D. T.; MOSS, J. E. The new protean career contract: helping organizations and employees adapt. Organizational Dynamics, v. 26, n. 3, p. 22-36, Winter, 1998.

HOLOVIAK, S.; GREENWOOD, D. Mid-career switching: who's doing it and the implications for businesses. American business perspectives, n. 220, p. 5-7, mar./apr. 2000.

KILIMNIK, Z.; MORAIS, L. O conteúdo significativo do trabalho como fator de qualidade de vida organizacional. Revista da Angrad, Rio de Janeiro, v. 1, n. 1, p. 64-74, 2000.

KILIMNIK, Z.; CASTILHO, I.; SANT’ANNA, A. Carreiras em Transformação: um estudo de trajetórias, âncoras e metáforas de carreira em associação a representações de competências profissionais. Comportamento Organizacional e Gestão, v. 12, n. 2, p. 257-280, 2006.

KILIMNIK, Z. M. et al. Representações sobre carreira, atividade docente e competências: um estudo com mestrandos em administração. In.: $30^{\circ}$ ENCONTRO ANUAL DA ASSOCIAÇÃO NACIONAL DOS PROGRAMAS DE PÓSGRADUAÇÃO EM ADMINISTRAÇÃO, 2006, Salvador. Anais... Salvador: ANPAD, 2006.

KILIMNIK, Z. M. et al. Seriam as âncoras de carreiras estáveis ou mutantes? Um estudo com profissionais de Administração em transição de carreira. Revista da ABOP, v. 9. p. 43-60, 2008.

LAWLER, E. F; PORTER, L. W. O efeito do desempenho na satisfação do trabalho. In.: LOBOS, J. A. Comportamento Organizacional. São Paulo: Atlas, 1978. p. 119-30.

LEVINE, David M.; BERENSON, Mark L.; STEPHAN, David. Estatística: teoria e aplicações usando microsoft excel em português. Rio de Janeiro: LTC, 2000. 811 p.

MALHOTRA, N. K. Pesquisa de marketing: uma orientação aplicada. 4. ed. Tradução de Laura Bocco. Porto Alegre: Bookman, 2006. 720 p.

MARTINS, H. Gestão de carreiras na era do conhecimento: abordagem conceitual \& resultados de pesquisa. Rio de Janeiro: Qualitymark, 2001. 
MALVEZZI, Sigmar. A construção da identidade do profissional no modelo emergente de carreira. Organização \& Sociedade, jan./abr. 2000, v. 7, n. 17, p. 137-143.

MCDONALD, P.; BROWN, K.; BRADLEY, L. Have traditional career paths given way to protean ones? Evidence from senior managers in the Australian public sector School of Management. Faculty of Business. Queensland University of Tecnology, Barisbane, Australia, november, 2004.

MAGUIRE, H. Psychological contracts: are they still relevant? Career Development International, v. 7, n. 3, p. 167-81, 2002.

OLIVEIRA, S. Tratado de Metodologia Científica. São Paulo: Pioneira, 1997.

REITMAN, F.; SCHNEER, J. A. The promised path: a longitudinal study of managerial careers, Journal of Managerial Psychology, v. 18, n. 1, p. 60-75, 2003.

RODRIGUES, C.; BOUZADA, V.; KILIMNIK, Z. Estilo de vida e segurança:

Seriam essas as âncoras dos futuros detentores de "carreiras proteanas ou sem fronteiras"? Um estudo comparativo entre alunos de graduação e de mestrado em Administração. Anais, 2007.

SCHEIN, E. H. Carrrer anchours: discovering your real values. Califórnia: University Associates, 1990.

SCHEIN, Edgar. Career anchors: discovering your real values. Revised Edition. San Diego: Pfeiffer \& Company, 1993.

STROH, L. K.; BRETT, J. M.; REILLY, A. H. Family structure, glass ceiling and traditional explanations for the differential rate of turnover of female and male managers, Journal of Vocational Behavior, v. 49, n. 1, p. 99-118.

VERGARA, Sylvia Constant. Projetos e relatórios de pesquisa em administração. 6. ed. São Paulo: Atlas, 2005. 